\title{
Polioencefalomalacia em caprinos e ovinos na região semi- árida do Nordeste do Brasil ${ }^{1}$
}

\author{
Everton F. Lima ${ }^{2}$, Franklin Riet-Correa ${ }^{3}$, Ivon M. Tabosa ${ }^{3}$, Antônio Flávio M. \\ Dantas $^{3}$, Josimar M. Medeiros ${ }^{3}$ e Gerôncio Sucupira Júnior ${ }^{3}$
}

\begin{abstract}
Lima E.F,, Riet-Correa F., Tabosa I.M., Dantas A.F.M., Medeiros J.M. \& Sucupira Júnior G. 2005. [Polioencephalomalacia in goats and sheep in the semiarid region of northeastern Brazil.] Polioencefalomalacia em caprinos e ovinos na região semi-árida do Nordeste do Brasil. Pesquisa Veterinária Brasileira 25(1):9-14. Centro de Saúde e Tecnologia Rural, Universidade Federal de Campina Grande, Campus de Patos, 58700-000 Patos, PB, Brazil. E-mail: riet@cstr.ufcg.edu.br

Seven outbreaks of polioencephalomalacia in goats and 3 in sheep are reported from the semiarid region of northeastern Brazil. Animals of different ages were affected in various seasons of the year. In 5 outbreaks the animals were supplemented with concentrate ration and in 5 others they were only grazing on pastures. In one outbreak sheep were supplemented with an energy-protein-mineral mixture containing $1.3 \%$ of sulfur flower. Clinical signs were characterized by blindness, depression, head pressing, circling, grinding of the teeth, incoordination, spastic paralysis, ataxia, depression of the palpebral and pupillary reflexes, lateral strabismus, nystagmus, and dilated pupils. Nine affected animals were treated with thiamine and dexamethasone; 7 of them recovered but 2 died. The diagnosis of the disease was based on the recovered animals after treatment and/or on the histologic lesions. The clinical course varied from 2 to 15 days. On three animals post-mortem examination was made. One had herniation of the cerebellum through the Foramen magnum and softening of the cerebral cortex. The cut surface of the cerebral cortex showed cavitation and yellowish discoloration. Another animal had only cerebellar herniation. In a third animal no gross lesions were observed. Histological changes in the 3 animals were laminar necrosis of the cerebral cortex, and in 2 malacia of the thalamus and the rostral colliculi was also observed. In 9 outbreaks the cause of the disease was not determined, but one was probably due to sulfur toxicosis caused by the high sulfur content of the energy-protein-mineral mixture containing $1.3 \%$ of sulfur flower $(96 \%$ sulfur) and $30 \%$ chicken litter ( $0.39 \%$ sulfur).
\end{abstract}

INDEX TERMS: Polioencephalomalacia, cortical necrosis, goats, sheep, sulfur poisoning, thiamine deficiency.

RESUMO.- Descrevem-se 7 surtos de polioencefalomalacia em caprinos e 3 surtos em ovinos no semi-árido nordestino. Foram afetados animais de diversas idades em diferentes épocas do ano. Em 5 surtos os animais eram suplementados com concentrados e em 5 consumiam somente pastagem. Em um dos surtos os ovinos estavam recebendo à vontade uma mistura múltipla contendo $1,3 \%$ de flor de enxofre. Os sinais clínicos caracterizaram-se por cegueira, depressão, pressão da cabeça contra objetos, andar em

\footnotetext{
${ }^{1}$ Recebido em 14 de julho de 2004.

Aceito para publicação em 9 de agosto de 2004.

${ }^{2}$ Aluno do Programa de Pós-Graduação em Ciência Veterinária, UFRPE.

${ }^{3}$ Curso de Medicina Veterinária, Centro de Saúde e Tecnologia Rural, Universidade Federal de Campina Grande, Campus de Patos, 58700-000 Patos, PB. *Autor para correspondência. E-mail: riet@cstr.ufcg.edu.br
}

círculos, ranger de dentes, incoordenação, paralisia espástica, ataxia, diminuição dos reflexos palpebral e pupilar, estrabismo lateral, nistagmo e pupilas dilatadas. De 9 animais tratados com tiamina e dexametasona, 7 se recuperaram e 2 morreram. 0 diagnóstico foi feito com base na recuperação após o tratamento e/ou a presença de alterações histológicas características. O curso clínico variou de 2 a 15 dias. Três animais foram necropsiados. Um animal apresentou herniação do cerebelo em direção ao Forame magno e amolecimento das circunvoluções cerebrais e, ao corte, coloração amarelada e cavitação da substância cinzenta do córtex. Outro animal apresentou somente herniação do cerebelo. No terceiro animal não foram observadas lesões macroscópicas. As alterações histológicas caracterizaram-se por necrose laminar do córtex cerebral e, em dois animais, por lesões de malácia no tálamo e colículo rostral. Desconhece-se a etiologia em 9 dos surtos estu- 
dados. Em outro se sugere que tenha sido causado por intoxicação por enxofre, contido principalmente na mistura múltipla constituída por com $1,3 \%$ de flor de enxofre ( $96 \%$ de enxofre) e $30 \%$ de cama de galinha $(0,39 \%$ de enxofre).

TERMOS DE INDEXAÇÃO: Polioencefalomalacia, necrose cortical cerebral, caprinos, ovinos, enxofre, deficiência de tiamina.

\section{INTRODUÇÃO}

Polioencefalomalacia (PEM) ou necrose cerebrocortical é uma enfermidade neurológica, não infecciosa, dos ruminantes que pode ser causada por: alterações no metabolismo da tiamina, associadas a dietas altas em concentrados, levando a acidose clínica ou subclínica, que reduz o número de microrganismos do rume que sintetizam tiamina, bem como permite o crescimento das bactérias que produzem tiaminase; ingestão de análogos da tiamina, como o amprólio; ingestão de vegetais contendo tiaminases; intoxicação por enxofre; privação de água e/ou intoxicação por cloreto de sódio; e intoxicação por chumbo (Carlton \& McGavin 1990, Smith \& Sherman 1994, Radostits et al 2000, Lemos \& Nakazato 2001). No Brasil, a PEM em bovinos é freqüente nas Regiões Centro-Oeste e Sudeste (Ferreira et al. 1986, Moro et al. 1994, Gonçalves et al. 2001, Nakazato et al. 2000) e foi diagnosticada, também, na Região Sul (Santos et al. 1983). Recentemente a doença foi também diagnosticada em ovinos, nas Regiões Centro-Oeste (Moscardini et al. 2003) e Nordeste (Nascimento et al. 2003). Tanto em bovinos quanto em ovinos não tem sido determinada a causa da enfermidade, exceto num surto observado no Rio Grande do Sul, que foi associado à ingestão excessiva de enxofre (Driemeier et al. 2001). Em caprinos a doença foi diagnosticada em animais que ingeriram Hovenia dulcis, a "uva-do-Japão" (Colodel et al. 1998).

O objetivo deste trabalho é de descrever surtos de polioencefalomalacia diagnosticados em caprinos e ovinos na região semi-árida do nordeste do Brasil, diagnosticados no Hospital Veterinário da Universidade Federal de Campina Grande, Campus de Patos, Paraíba, no período de abril de 1997 a janeiro de 2004.

\section{MATERIAL E MÉTODOS}

Este trabalho inclui todos os casos de polioencefalomalacia (PEM) em caprinos e ovinos diagnosticados na Clínica de Ruminantes e no Laboratório de Anatomia Patológica da Universidade Federal de
Campina Grande, Campus de Patos, Paraíba, durante o período de abril de 1997 a janeiro de 2004. Os dados epidemiológicos e os principais sinais clínicos foram coletados junto aos proprietários dos animais ou aos veterinários que remeteram os casos. Todos os animais que chegaram vivos ao Hospital Veterinário (pelo menos um de cada surto) foram examinados clinicamente, realizando-se exame completo do sistema nervoso. Os animais suspeitos de PEM foram tratados com 10 a $20 \mathrm{mg}$ por $\mathrm{kg}$ de peso vivo de tiamina (vitamina $\mathrm{B}_{1}$ ) e com $0,2 \mathrm{mg} / \mathrm{kg} / \mathrm{pv}$ de dexametasona por via intramuscular. $O$ tratamento era repetido duas vezes ao dia até a recuperação completa do animal. Os animais que apresentaram clinicamente sinais compatíveis com a enfermidade e que responderam ao tratamento foram considerados como afetados por PEM. Foram necropsiados dois caprinos e um ovino, que morreram, e coletados o encéfalo, a medula espinhal e fragmentos dos diferentes órgãos, que foram fixados em formol tamponado a $10 \%$. Após a fixação, o encéfalo foi cortado em seções transversais de 3-4 mm. Seções do córtex cerebral (frontal, parietal, temporal e occipital), cápsula interna e núcleos da base, tálamo, colículo rostral, ponte, cerebelo, medula oblonga (bulbo) e, em um caso, a medula cervical, dorsal e lombar, foram estudados histologicamente. Os tecidos foram desidratados, embebidos em parafina e cortados em seç̧ões de 5 micra de espessura e corados pela técnica de hematoxilina/eosina (HE) para serem examinados ao microscópio óptico.

\section{RESULTADOS}

A idade, sexo, raça e espécie dos animais afetados, número de animais nos rebanhos, época do ano, município de origem e freqüência da doença de 10 surtos de PEM diagnosticados no período de abril de 1997 a janeiro de 2004 são apresentados no Quadro 1.

O sistema de criação, tipo de alimentação e suplementação mineral são relatados no Quadro 2. Durante o período de janeiro de 2002 a janeiro de 2004 foram diagnosticados no Hospital Veterinário 163 casos de doenças de ovinos e 256 casos de doenças de caprinos, portanto, os 7 casos de PEM em caprinos representam $2,73 \%$ de todos os casos, enquanto que, os 3 casos de ovinos representam $1,84 \%$ dos diagnósticos.

Os sinais clínicos observados, a evolução clínica até a morte ou a recuperação e a resposta ao tratamento constam do Quadro 3 e das Figuras 1 e 2.

As alterações macroscópicas observadas nos 3 casos necropsiados foram amolecimento das circunvoluções cerebrais

Quadro 1. Dados epidemiológicos dos surtos de PEM em pequenos ruminantes no período de 1997 a 2004 no semi-árido do Nordeste do Brasil

\begin{tabular}{|c|c|c|c|c|c|c|c|c|c|}
\hline $\begin{array}{c}\text { Surto } \\
n^{\circ}\end{array}$ & Espécie & Raça & Sexo & Idade & $\begin{array}{c}\text { Rebanho } \\
\text { (meses) }\end{array}$ & Época & Doentes & Mortos & Município \\
\hline 1 & Caprina & SRD & M & 6 & $\mathrm{Ni}^{\mathrm{a}}$ & Abr. 1997 & 6 & 2 & Olho D’Água, PB \\
\hline 2 & Ovina & Sta Inês & M & 28 & $\mathrm{Ni}$ & Jan. 2002 & $\mathrm{Ni}$ & $\mathrm{Ni}$ & S. José Espinharas, PB \\
\hline 3 & Caprina & SRD & $\mathrm{F}$ & 6 & 15 & Ago. 2002 & $\mathrm{Ni}$ & $\mathrm{Ni}$ & Patos, PB \\
\hline 4 & Caprina & Boer & $\mathrm{F}$ & 50 & 42 & Out. 2002 & 6 & 4 & Várzea, PB \\
\hline 5 & Caprina & SRD & $\mathrm{F}$ & 18 & 5 & Nov. 2002 & $\mathrm{Ni}$ & $\mathrm{Ni}$ & S. José Bomfim, PB \\
\hline 6 & Caprina & SRD & $\mathrm{F}$ & 36 & $\mathrm{Ni}$ & Mar. 2003 & $\mathrm{Ni}$ & $\mathrm{Ni}$ & Cabaceiras, PB \\
\hline 7 & Ovina & Sta Inês & M & 24 & & Jul. 2003 & $\mathrm{Ni}$ & $\mathrm{Ni}$ & Afogados Ingazeira, PE \\
\hline 8 & Caprina & SRD & $\mathrm{F}$ & 6 & 5 & Nov. 2003 & $\mathrm{Ni}$ & $\mathrm{Ni}$ & Patos, PB \\
\hline 9 & Ovina & Sta Inês & $\mathrm{F}$ & Diversas & 50 & Dez. 2003 & 6 & 6 & Monteiro, PB \\
\hline 10 & Caprina & Anglo Nubiana & $\mathrm{F}$ & 18 & 70 & Jan. 2004 & $\mathrm{Ni}$ & $\mathrm{Ni}$ & Patos, PB \\
\hline
\end{tabular}

${ }^{\mathrm{a}} \mathrm{Ni}=$ Não informado. 

Quadro 2. Tipo de alimentação, sistema de criação e suplementação mineral
nas fazendas onde ocorreram os surtos de PEM em pequenos ruminantes no
período de 1997 a 2004 no semi-árido do Nordeste do Brasil

\begin{tabular}{|c|c|c|c|c|c|}
\hline $\begin{array}{c}\text { Surto } \\
n^{0}\end{array}$ & Espécie & $\begin{array}{l}\text { Idade } \\
\text { (meses) }\end{array}$ & $\begin{array}{l}\text { Sistema de } \\
\text { criação }\end{array}$ & Tipo de alimentação & $\begin{array}{c}\text { Suplementação } \\
\text { mineral }\end{array}$ \\
\hline 1 & Caprina & 6 & Extensivo & Pasto nativo & $\mathrm{Ssm}^{\mathrm{a}}$ \\
\hline 2 & Ovina & 28 & Intensivo & Volumoso + Concentrado & Sal mineral \\
\hline 3 & Caprina & 6 & Semi-intensivo & Pasto nativo + Concentrado & SM \\
\hline 4 & Caprina & 50 & Extensivo & Pasto nativo & Sal mineral \\
\hline 5 & Caprina & 18 & Semi-intensivo & Pasto nativo + Concentrado & Sem informação \\
\hline 6 & Caprina & 36 & Intensivo & Capim elefante + Farelo de milho & Sal mineral \\
\hline 7 & Ovina & 24 & Intensivo & Volumoso + concentrado & Ssm \\
\hline 8 & Caprina & 6 & Extensivo & Pasto nativo & Ssm \\
\hline 9 & Ovina & Diversas & Extensivo & Pasto nativo & Mistura múltiplab \\
\hline 10 & Caprina & 18 & Extensivo & Pasto nativo & $\mathrm{SM}$ \\
\hline
\end{tabular}

assm = Sem suplementação mineral.

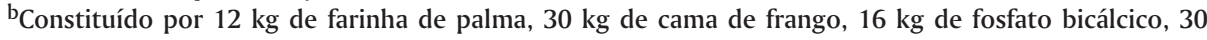
$\mathrm{kg}$ de $\mathrm{NaCl}, 10 \mathrm{~kg}$ de uréia, $1,3 \mathrm{~kg}$ de flor de enxofre, $600 \mathrm{~g}$ de sulfato de zinco, e $20 \mathrm{~g}$ de sulfato de cobalto.

Quadro 3. Sinais clínicos, curso da doença e resposta à tiamina dos surtos de PEM em pequenos ruminantes no período de 1997 a 2004 no Semi-Árido do Nordeste do Brasil

\begin{tabular}{l} 
Sinais clínicos \\
\hline Andar em círculo \\
Anorexia \\
Ataxia \\
Atonia ruminal \\
Cauda em bandeira \\
Cegueira \\
Depressão \\
Decúbito \\
Incoordenação \\
Estrabismo lateral \\
Movimentos de pedalagem \\
Opistótono \\
Nistagmo \\
Paralisia espástica \\
Pressão da cabeça contra objetos \\
Pupilas dilatadas \\
Ranger de dentes \\
Salivação \\
Diminuição da sensibilidade dos \\
reflexos palpebral e pupilar \\
Curso da doença (dias) \\
Resposta à tiamina \\
\hline a
\end{tabular}

\begin{tabular}{cccccccccc}
\multicolumn{10}{c}{ Surtos } \\
\hline 1 & 2 & 3 & 4 & 5 & 6 & 7 & 8 & 9 & 10 \\
- & - & + & + & - & - & - & - & - & - \\
- & - & - & + & - & - & - & + & - & - \\
+ & + & + & - & - & - & + & + & - & + \\
- & - & + & + & - & - & - & - & - & - \\
- & - & - & - & + & - & - & - & - & - \\
+ & + & + & + & - & - & + & + & - & + \\
- & + & + & + & - & - & + & - & - & + \\
+ & - & - & - & + & + & + & - & + & + \\
- & - & - & - & - & - & + & + & - & - \\
- & - & - & - & + & - & - & - & - & - \\
- & - & - & - & + & - & - & - & + & - \\
- & - & - & - & + & + & - & - & - & + \\
- & - & - & - & - & - & - & - & + & - \\
- & - & - & - & + & + & - & - & - & - \\
+ & + & - & + & - & - & - & - & - & - \\
- & - & - & - & - & - & + & - & - & - \\
- & - & + & + & - & - & - & - & - & - \\
- & - & - & - & - & - & + & - & - & - \\
- & - & + & - & - & - & - & + & - & - \\
2 & 3 & 15 & 3 & 3 & 4 & 2 & 10 & $\mathrm{Si}^{\mathrm{a}}$ & 2 \\
- & + & + & + & + & - & + & + & $\mathrm{Nt}^{\mathrm{b}}$ & + \\
& & & & & & & & &
\end{tabular}

a Sem informação.

b Não tratado.

(Surto 6), herniação do cerebelo em direção ao forame magno (Surtos 6 e 9, Fig. 3) e, ao corte, coloração amarelada e cavitação da substância cinzenta (Surto 6). Em um animal (Surto 1) não foram observadas lesões macroscópicas.

Ao exame histológico, os 3 animais estudados apresentavam necrose laminar do córtex cerebral afetando todas as camadas ou somente as intermediarias, caracterizada por palidez (perda da eosinofilia) do córtex, aumento dos espaços perivasculares e perineuronais, vacuolização do neurópilo, presença de neurônios eosinofílicos, hiperplasia e tumefação das células endoteliais dos vasos sanguíneos (Fig. 4). Nos Sur-

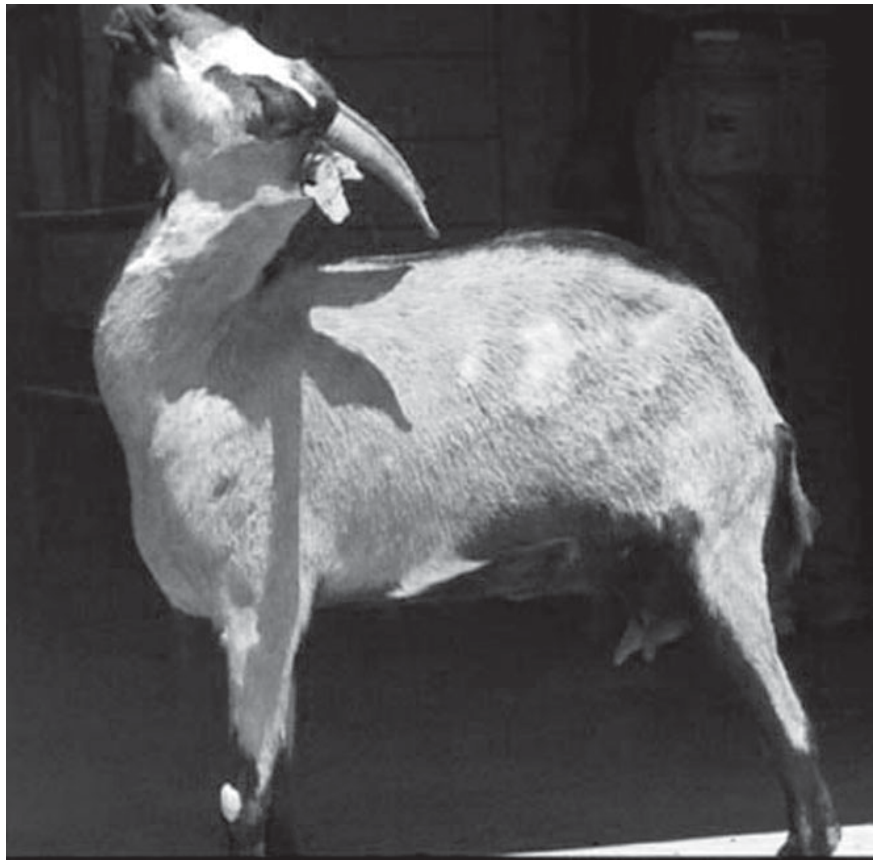

Fig. 1. Polioencefalomalacia em caprino do Surto 5. Observa-se opistótono devido, provavelmente, à herniação do cerebelo através do forame magno.

tos 1 e 6 havia infiltração de células Gitter e cavitação (Fig. 5). Também foram observados esferóides axonais, hemorragias e discretos astrócitos reativos, gliose e infiltrado inflamatório ao redor de vasos e meninges. Nos 3 animais, as lesões do córtex eram semelhantes nas 4 regiões estudadas (frontal, occipital, temporal e parietal). No colículo rostral dos Surtos 6 e 9 havia malácia caracterizada por neurônios eosinofílicos, hiperplasia do endotélio e raros esferóides axonais; alguns vasos apresentavam discreto acúmulo perivascular de células mononucleares. Alterações semelhantes foram observadas no tálamo no Surto 9. Neste último foram observadas, também, áreas multifocais de malácia abrangendo as 3 camadas de substância cinzenta e a substância branca cerebelar. 

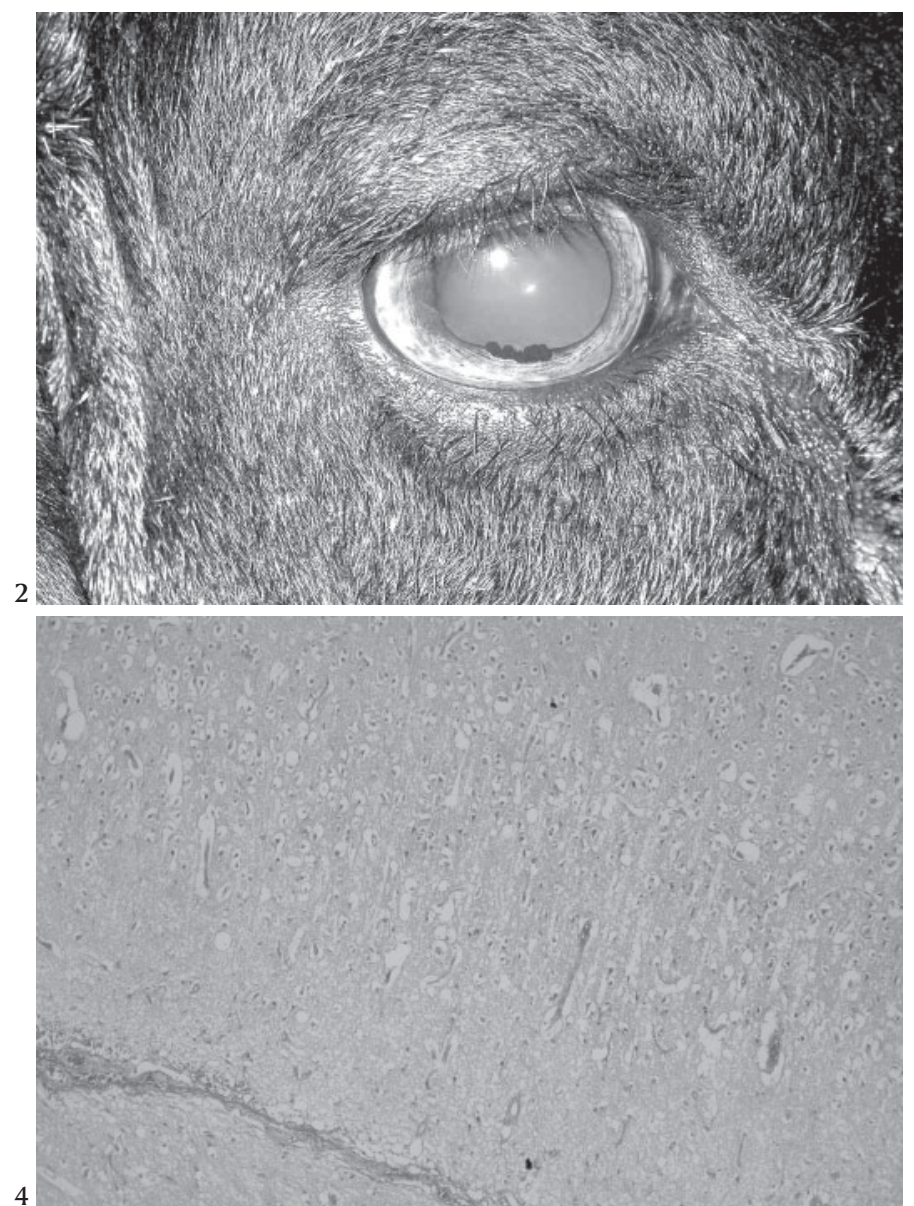

Fig. 2. Polioencefalomalacia em ovino do Surto 7. Observa-se dilatação da pupila causada, provavelmente, por compressão do núcleo do nervo oculomotor em consequiência do edema cerebral.

Fig. 4. Lesão recente de polioencefalomalacia no córtex cerebral, com vacuolização do pericário e aumento dos espaços perivasculares e perineuronais e distribuição laminar (Caprino do Surto 6) .

\section{DISCUSSÃO}

A polioencefalomalacia (PEM) é uma doença pouco diagnosticada em pequenos ruminantes, tendo sido descrita somente em ovinos nas Regiões Centro-Oeste (Moscardini et al. 2003) e Nordeste (Nascimento et al. 2003). $O$ único diagnóstico de PEM realizado em caprinos no Brasil foi associado à ingestão de Hovenia dulcis, sem que fosse determinado o princípio ativo da planta (Colodel et al. 1998). Neste trabalho, os diagnósticos de 7 casos de PEM em caprinos e 3 casos em ovinos sugerem que a doença, pelo menos na região semi-árida, é freqüente e, provavelmente, tenha passado despercebida anteriormente. Em outros países a PEM em ovinos tem sido associada à intoxicação por enxofre (Rousseaux et al. 1991, McAllister et al. 1992, Bulgin et al. 1996, Low et al. 1996) e tanto em ovinos quanto em caprinos é também associada à deficiência ou inibição da atividade de tiamina (Smith \& Shermann 1994). Em relação à causa da enfermidade na região semi-árida, a mesma foi identificada presuntivamente em um surto em que ovinos estavam ingerindo uma mistura
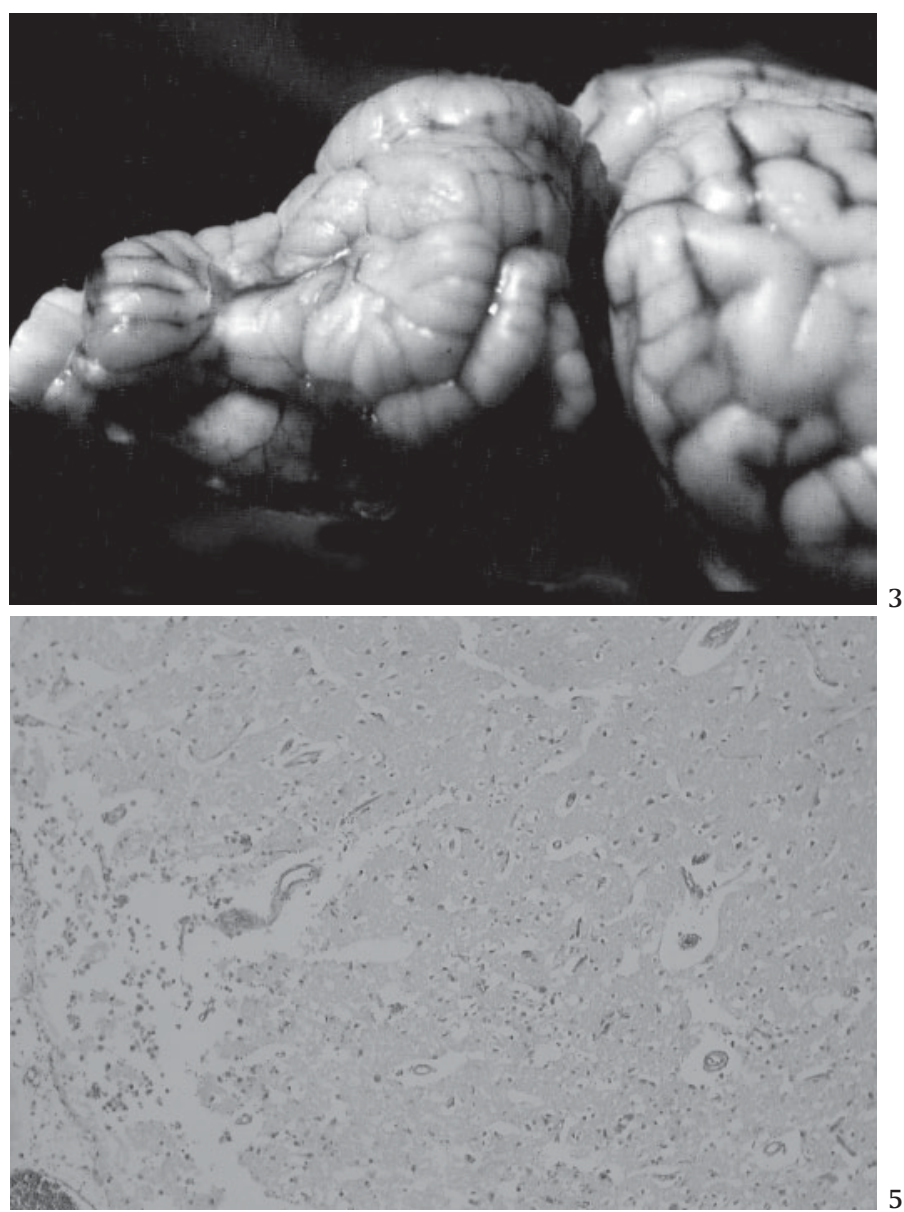

Fig. 3. Polioencefalomalacia em ovino do Surto 9. Encéfalo. Conificação do cerebelo devido à herniação do mesmo através do forame magno.

Fig. 5. Áreas de malacia com vacuolização do pericário, aumento dos espaços perivasculares, hiperplasia do endotelio vascular e cavitação com presença de numerosas células Gitter nas camadas superficiais do córtex cerebral (Caprino do Surto 6).

múltipla constituída por $12 \mathrm{~kg}$ de farinha de palma, $30 \mathrm{~kg}$ de cama de frango, $16 \mathrm{~kg}$ de fosfato bicálcico, $30 \mathrm{~kg}$ de $\mathrm{NaCl}, 10 \mathrm{~kg}$ de uréia, $1,3 \mathrm{~kg}$ de flor de enxofre, $600 \mathrm{~g}$ de sulfato de zinco e 20 $\mathrm{g}$ de sulfato de cobalto. Este suplemento estava sendo dado à vontade e o consumo, de acordo com um trabalho no qual administrou-se uma mistura semelhante (Salomão et al. 1997), pode ser estimado em, no mínimo, $150 \mathrm{~g}$ por cabeça por dia. Considerando-se que um ovino de $45 \mathrm{~kg}$ deve ingerir aproximadamente $1-1,5 \mathrm{~g}$ por dia de $\mathrm{S}(0,1-0,15 \%$ da dieta), o $\mathrm{S}$ administrado somente na flor de enxofre corresponde a $1,87 \mathrm{~g}$ por dia. Por outro lado, a cama de frango contém em média $0,39 \%$ de $S$, com um máximo de 0,44\% e um mínimo de 0,33\% (Ortolani 2001b), que, para a estimativa de um consumo de $150 \mathrm{~g}$ da mistura múltipla, representa a ingestão de mais $175 \mathrm{mg}$ de $S$. A isto, agrega-se o $S$ contido no sulfato de zinco (106 mg), no sulfato de cobalto $(3,4$ $\mathrm{mg}$ ) e nos outros componentes da dieta e na água. Considerando esses valores e um consumo de matéria seca equivalente a $2 \%$ do peso vivo, os ovinos estariam ingerindo, somente por concei- 
to do $S$ da mistura múltipla, $0,24 \%$ deste mineral na dieta. A esses valores deve ser agregado o $\mathrm{S}$ contido nos outros nutrientes da mistura múltipla, nas pastagens e na água. Apesar dos níveis de S dos outros nutrientes e da água serem desconhecidos é provável que a ingestão de $\mathrm{S}$ por esses ovinos estivesse acima dos níveis tóxicos ( $0,4 \%$ da dieta). No Brasil, não tem sido determinada a participação do $\mathrm{S}$ na etiologia da poliencefalomalacia em ruminantes a pastejo, no entanto, em outros países a doença ocorre freqüentemente pelo consumo de águas e/ou pastagens contendo níveis altos de enxofre e para o diagnóstico da mesma é necessário somar o conteúdo de $\mathrm{S}$ dos diferentes elementos da dieta, pasto, água e suplementos (Gould 1998). É freqüente encontrar $1,3 \%$ de flor de enxofre nas misturas múltiplas recomendadas para pequenos ruminantes no semi-árido. Perante essa realidade é evidente a necessidade de reavaliar a quantidade de $\mathrm{S}$ nos suplementos. Enquanto não se obtém dados experimentais a respeito recomenda-se seguir as orientações da Embrapa (1995) para gado de corte: quando utilizar uréia, agregar $4 \mathrm{~kg}$ de flor de enxofre ou $15 \mathrm{~kg}$ de sulfato de amônia para cada 100 $\mathrm{kg}$ de uréia. Neste caso o $S$ é necessário para manter uma relação de 15 partes de $\mathrm{N}$ para cada parte de $\mathrm{S}$. Portanto, as misturas múltiplas com $10 \mathrm{~kg}$ de uréia para $100 \mathrm{~kg}$ de mistura devem ser formuladas com $400 \mathrm{~g}$ de flor de enxofre ou $1,5 \mathrm{~kg}$ de sulfato de amônia ou sulfato de cálcio.

Nos demais surtos não foi determinada a causa da enfermidade. Uma possibilidade é que alguns desses surtos tenham sido também causados pela ingestão exagerada de enxofre. Para determinar essa possibilidade seria necessário, em surtos que venham a ocorrer no futuro, determinar a concentração de $S$ na pastagem, nos concentrados, na água e no sal mineral. Outra causa de PEM é a destruição ou menor produção de tiamina no rume. Estes quadros são freqüentes em erros no manejo nutricional, incluindo alimentação com altas quantidades de concentrados e modificações bruscas na dieta, sem adaptação prévia. É provável que os 5 surtos (Quadro 2) nos que os animais estavam sendo suplementados com concentrado tenham sido causados por distúrbios alimentares, no entanto nos demais surtos os animais estavam a campo, sem serem suplementados. Outra possibilidade é que haja, na área onde ocorreram os surtos, plantas que contenham tiaminase. Na Austrália, Marsilea drummondii tem sido associada à ocorrência da doença em ovinos (Radostits et al 2000). Pteridium spp e Equisetum spp, plantas que ocorrem no Brasil e que contêm tiaminases (Radostits et al. 2000), não são encontradas na região. A resposta positiva ao tratamento com tiamina sugere que a doença fosse causada por uma deficiência de tiamina, no entanto, deve-se considerar que animais intoxicados com $\mathrm{S}$, também respondem ao tratamento com vitamina $B_{1}$ (Bulgin et al. 1996, Low et al. 1996). Um fato importante é que a PEM causada por deficiência de tiamina é mais freqüente em ruminantes jovens, bem nutridos (Carlton \& McGavin 1990, Radostits et al. 2000), enquanto que a intoxicação por S afeta animais de diferentes idades (Radostits et al 2000). Cinco dos surtos descritos neste trabalho ocorreram em animais de 2 anos ou mais, enquanto que os outros 5 surtos ocorreram em animais com menos de 24 meses de idade, no entanto, em 3 destes últimos os animais estavam em regime extensivo de campo. Em relação ao tipo de criação fica evidente que a doença afeta rebanhos com diferentes números de animais, variando de 5 a 70 cabeças (Quadro 1). Também não se observam diferenças quanto à época de ocorrência da enfermidade, já que foram registrados surtos durante todo o ano, sendo que 6 surtos ocorreram durante a época seca e 4 durante a época de chuvas (Quadro 1). Na região semi-árida a época das chuvas vai de janeiro/fevereiro a março/abril.

Em relação à freqüência dos sinais clínicos observados os mais freqüientes foram cegueira (70\% dos casos), decúbito (60\%), ataxia e outras alterações proprioceptivas (60\%) e depressão (50\%). Outros sinais menos freqüentes foram opistótono e pressão da cabeça contra objetos (30\% dos casos), andar em círculos, anorexia, atonia ruminal, incoordenação, movimentos de pedalagem, paralisia espástica, ranger de dentes, diminuição da sensibilidade dos reflexos palpebral e pupilar (20\%) e cauda em bandeira, estrabismo lateral, nistagmo, pupilas dilatadas e salivação (10\%). Sinais característicos de alterações cerebrais (cegueira, depressão, pressão da cabeça contra objetos, andar em círculos, ranger de dentes) ocorrem em conseqüência da lesão primária de PEM no córtex cerebral, enquanto que os sinais referentes ao tronco encefálico (incoordenação, paralisia espástica, ataxia, diminuição dos reflexos palpebral e pupilar, estrabismo lateral, nistagmo e pupilas dilatadas) ocorrem em conseqüiência da compressão do tronco encefálico por edema cerebral, ou por lesões profundas de PEM. O opistótono é causado, provavelmente, pela compressão do cerebelo durante a herniação do mesmo. Apesar de que esses sinais clínicos são sugestivos de PEM, a doença pode ser confundida com outras enfermidadfes do sistema nervoso, freqüentes na região semiárida, como raiva, tétano, botulismo, abscessos, listeriose e intoxicações por Ipomoea spp. Nestes casos o tratamento precoce é um fator importante, tanto para recuperar o animal, quanto para estabelecer o diagnóstico correto.

As alterações histológicas dos 3 casos estudados, caracterizadas principalmente por necrose laminar do córtex cerebral, são semelhantes às descritas por outros autores (Carlton \& McGavin 1990, McAllister et al. 1997), no entanto, chama a atenção à presença de lesões profundas de malácia no tálamo e nos tubérculos quadrigêmeos. Lesões profundas no núcleo caudato, corpo caloso, tálamo, na substância nigra, no colículo e na ponte têm sido descritas na intoxicação por enxofre (Rousseaux et al. 1991, Low et al. 1996). Alguns autores mencionam que a presença dessas lesões profundas pode diferenciar a intoxicação por $\mathrm{S}$ da $\mathrm{PEM}$ associada à tiamina, pois nesta última não ocorrem lesões profundas (Loneragan et al. 1998). As lesões multifocais de malácia observadas no cerebelo são aparentemente causadas pela herniação do cerebelo através do forame magno.

\section{REFERÊNCIAS}

Bulgin M.S., Lincoln S.D. \& Mather G. 1996. Elemental sulfur toxicosis in a flock of sheep. J. Am. Vet. Med. Assoc. 208(7):1063-1065.

Carlton \& McGavin M.D. 1990. Patologia Veterinária Especial de Thomson. $2^{\mathrm{a}}$ ed. ArtMed, Porto Alegre. 672p.

Colodel E.M., Loretti A.P., Cruz C.E.F. \& Driemeier D. 1998. Polioencefalomalacia em caprinos associada à ingestão de Hovenia dulcis (“Uva-do-Japão”). Bolm 18, Laboratório Regional de Diagnóstico, Pelotas, p.35-42. 
Driemeir D. \& Loretti A.P. 2001. Intoxicação por enxofre (polioencefalomalacia). Anais do $10^{\circ}$ Encontro Nacional de Patologia Veterinária, Pirassununga, SP, p.245-246.

Embrapa 1995. Suplementação mineral racional. Gado de Corte Divulga. Disponível em http://www.cnpgc.embrapa.br/publicações

Ferreira F.A., Coelho H.E. \& Bastos J.E.D. 1986. Polioencefalomalacia em bovinos no Estado de Minas Gerais. Arq. Bras. Med. Vet. Zootec. 38(5):693700 .

Gonçalves R.C., Viana L., Sequeira J.L., Bandarra E.P., Chiacchio S.B. \& Kuchembuck M.R.G. 2001. Aspectos clínicos, anatomopatológicos e epidemiológicos da polioencefalomalacia em bovinos, na Região de Botucatu, SP. Veterinária Notícias 7(2):53-57.

Gould D.H. 1998. Poliencephalomalacia. J. Anim. Sci. 76:309-314.

Lemos R.A.A. \& Nakazato, L. 2001. Polioencefalomalacia, p. 547-553. In: Riet-Correa, F.,Schild A.L., Mendez M.C. \& Lemos R.A.A. (ed.) Doenças de Ruminantes e Eqüinos. Vol.2. 2 ${ }^{\underline{a}}$ ed. Varela, São Paulo. 574p.

Loneragan G.H., Gould D.H., Callan R.J., Sigudson C.J. \& Hamar D.W. 1998. Association of excess sulfur intake and an increase in hydrogen sulfide concentrations in the ruminal gas cap of recently weaned beef calves with polioencephalomalacia. J. Am. Vet. Med. Assoc. 213(11):1599-1604.

Low J.C., Scott P.R., Howie F., Lewis M., FitzSimons J. \& Spence J.A. 1996. Sulphur-induced polioencefalomalacia in lambs. Vet. Rec. 138:327-329.

McAllister M.M., Gould D.H. \& Hamar D.W. 1992, Sulphide-induced polioencephalomalacia in lambs. J. Comp. Path. 106:267-278.

McAllister M.M., Gould D.H., Raisbeck M.F., Cummings B.A. \& Lonergan J.H. 1997. Evaluation of ruminal sulfide concentrations and seasonal outbreaks of polioencefalomalacia in beef cattle in a feedlot. J. Am. Vet. Med. Assoc. 211(10):1275-1279.

Moro L., Nogueira R.H.G., Carvalho A.U. \& Marques D.C. 1994. Relato de três casos de polioencefalomalacia em bovinos. Arq. Bras. Med. Vet. Zootec. 46(4):409-416.

Moscardini A.R.C., Paludo G.R., Perecmanis S., Reis Jr. J.L., Heinemann M.B., Zambrano M., Araújo G.R.S., Cunha P.H.J., França R.O., Ribeiro L., Ferreira II R.F \& Borges J.R.J. 2003. Doenças com sinais neurológicos em ovinos no DF e Entorno. Anais do $11^{\circ}$ Congresso Latinoamericano de Buiatria, Salvador, p.19.

Nakazato L., Lemos R.A.A. \& Riet-Correa F. 2000. Polioencefalomalácia em bovinos no Mato Grosso do Sul e São Paulo. Pesq. Vet. Bras. 20(3):119-125.

Nascimento I.A., Afonso J.A., Tokarnia C.H., Mendonça C.L., Costa N.A., Souza M.I., Oliveira L.G.L., Vieira A.C.S. \& Pereira A.L.L. 2003. Polioencefalomalácia em ovinos. Anais do 5o Congresso Pernambucano de Medicina Veterinária, Recife, p.316.

Ortolani E.L. 2001b. Enfermidades causadas pelo uso inadequado da "cama de frango" na alimentação de ruminantes. Revta CFMV, Brasília, 7(22):4148 .

Radostits E.M., Gay C.C., Blood D.C. \& Hinchcliff K.W. 2000. Veterinary Medicine. 9th ed. W.B. Saunders, London, p. 501-550.

Russeaux C.G., Olkowski A.A., Chauvet A., Gooneratne S.R. \& Christenson D.A. 1991. Ovine polioencefalomalacia associated with dietary sulphur intake. J. Vet. Med. A 38:229-239.

Salomão J.A.F., Miranda R.M. \& Lopes H.O.S. 1997. Influência da suplementação com mistura protéica-energética-mineral no desempenho de ovelhas em final de gestação. Anais da $33^{\underline{a}}$ Reunião Soc. Bras. Zootecnia, Fortaleza, Ceará, p. 191-193.

Santos M.N., Jardim Filho J.O. \& Grando F.A. 1983. Polioencefalomalácia em bovinos no Rio Grande do Sul. Pesq. Vet. Bras. 3(2):37-39.

Smith M.C. \& Sherman D.M. 1994. Goat Medicine. Lea \& Febiger, Philadelphia, p.535-540. 